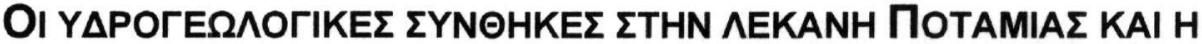

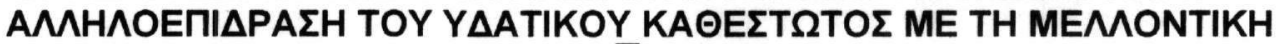

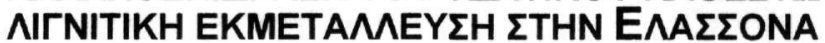

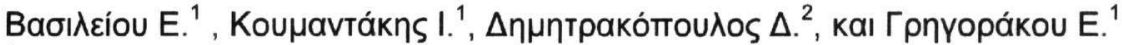

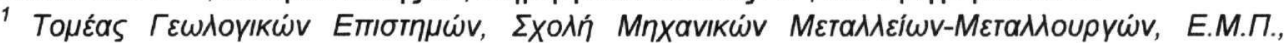

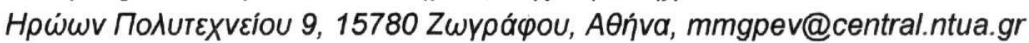

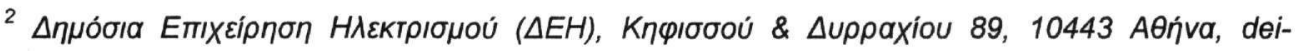 \\ teym@otenet.gr
}

\section{ПЕРІ $\Lambda \mathrm{H} \Psi \mathrm{H}$}

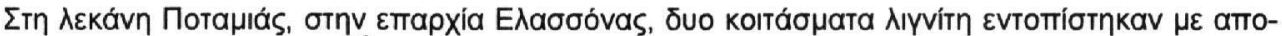

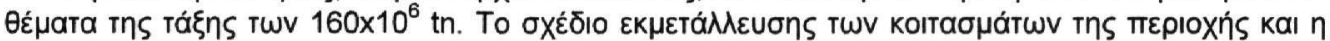

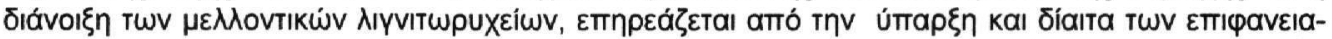

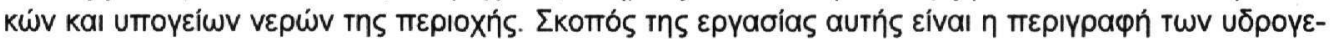

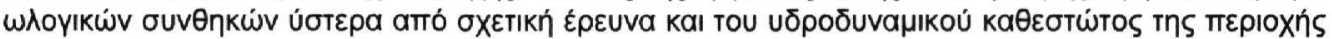

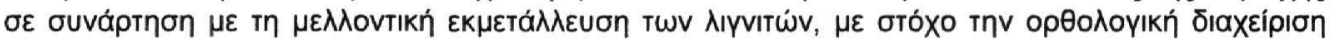

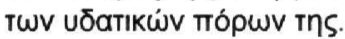

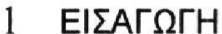

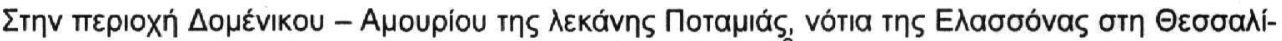

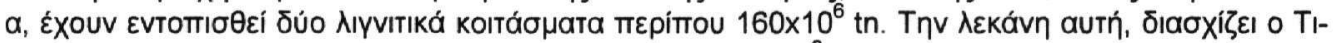

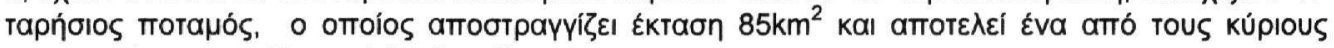

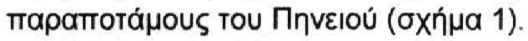

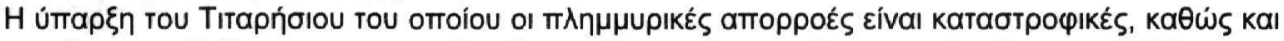

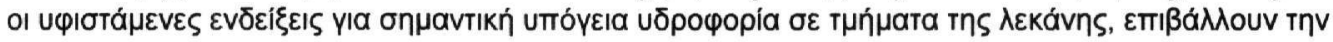

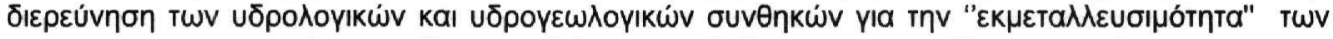

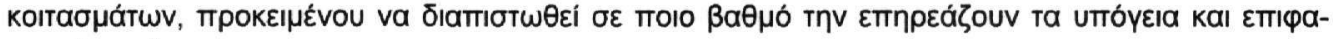
veıакá vepá.

\section{2 ГE $\Omega \wedge O \Gamma I K E \Sigma \Sigma Y N O H K E \Sigma$}

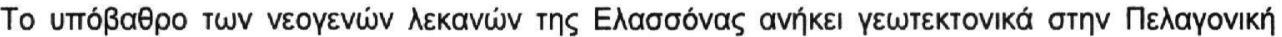

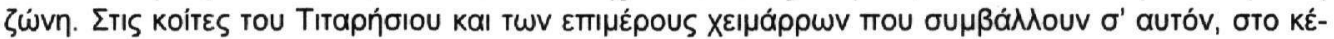

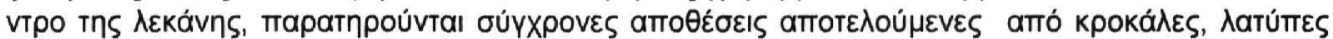

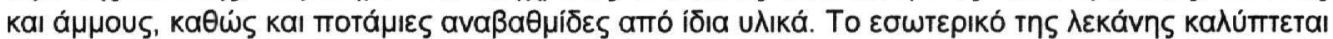

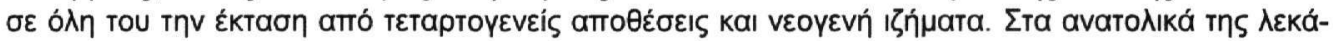

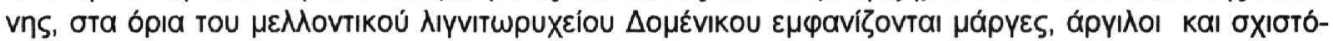

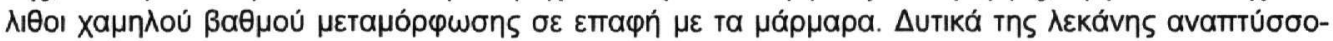

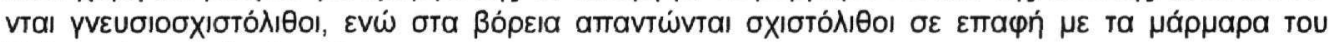

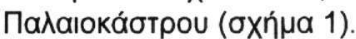

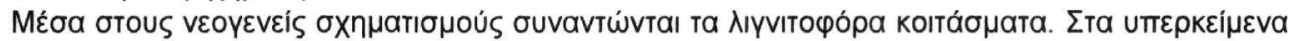

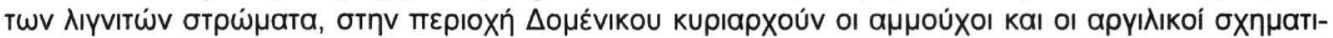

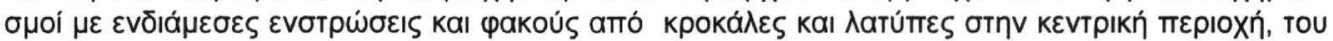

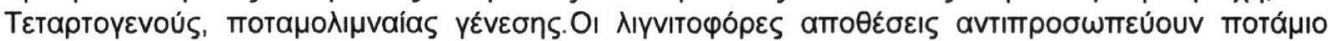

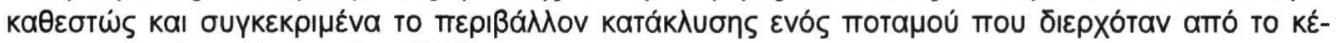

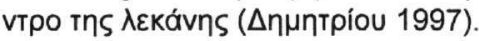



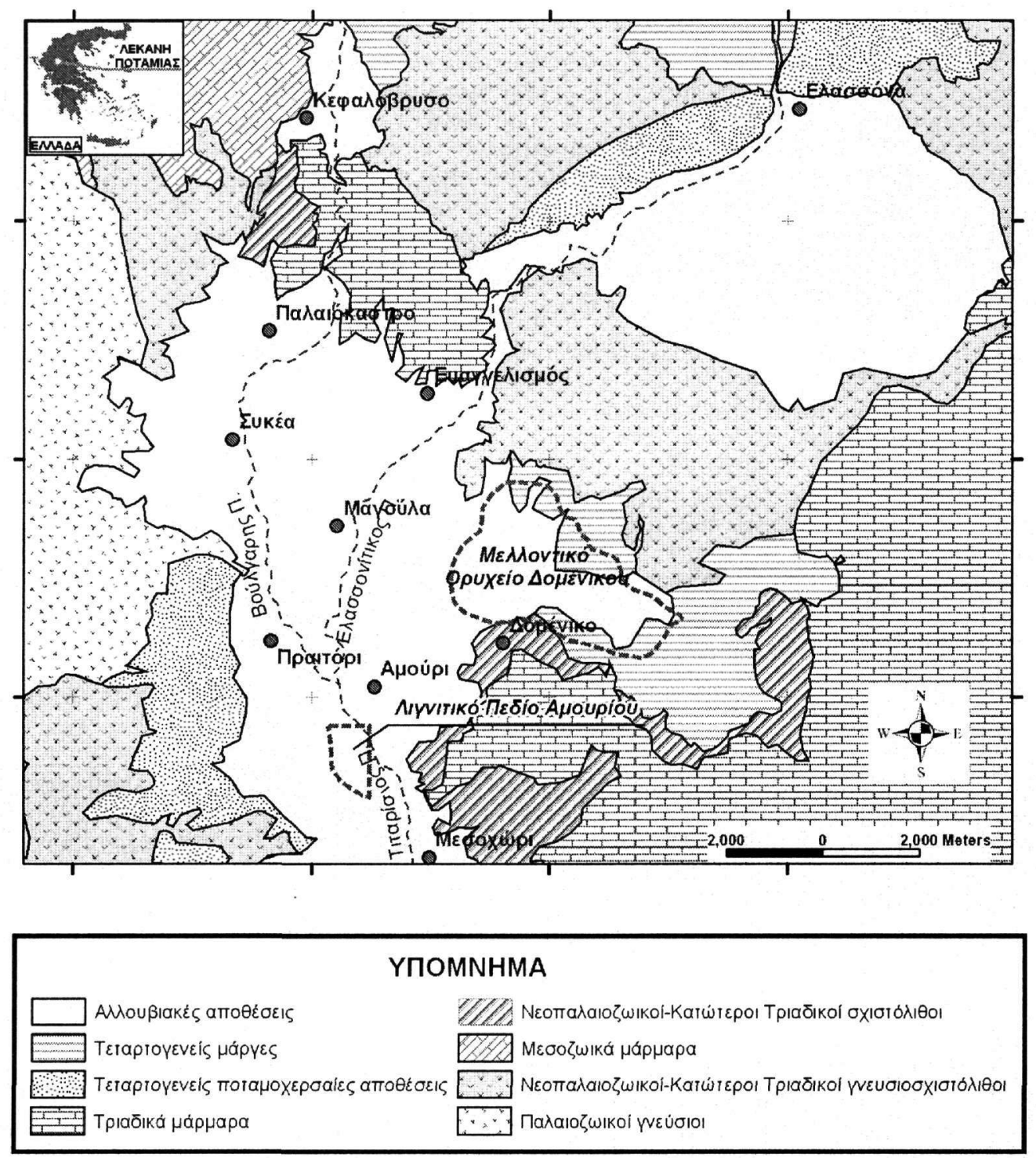

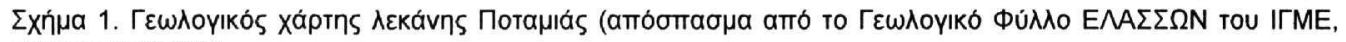
к入інака 1:50.000)

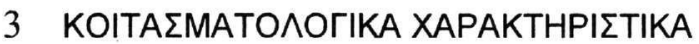

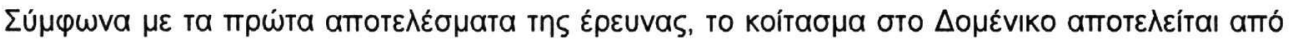

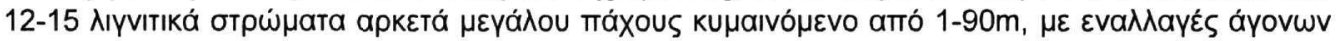

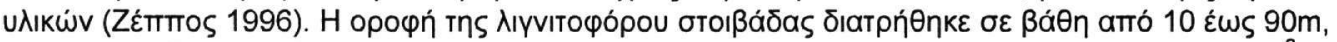

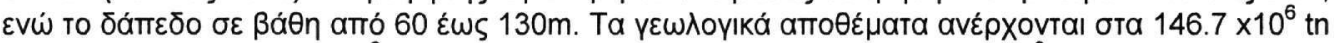

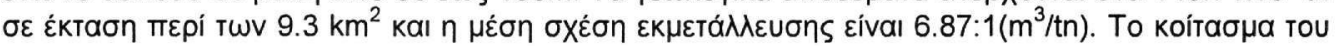

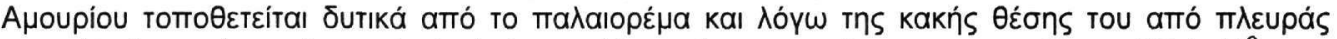

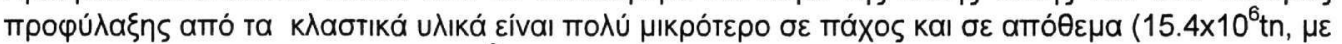

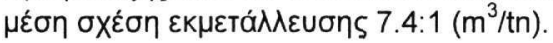




\section{Y $\triangle \mathrm{PO} Е \Omega \wedge O \Gamma I K E \Sigma \Sigma Y N \Theta H K E \Sigma$}

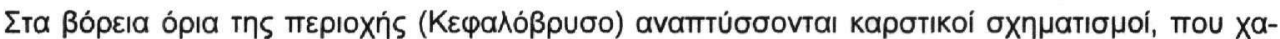

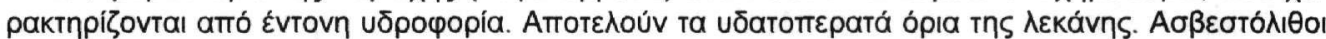

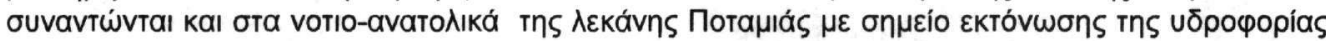

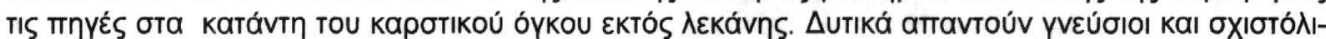

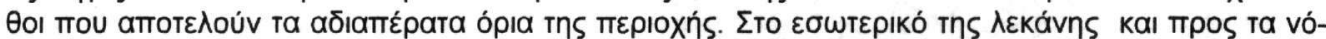

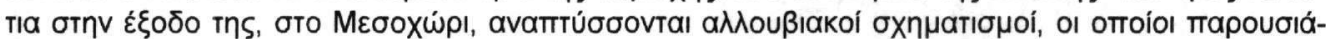

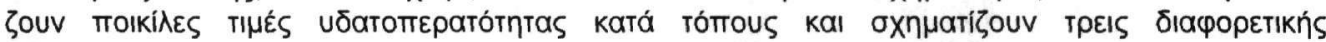

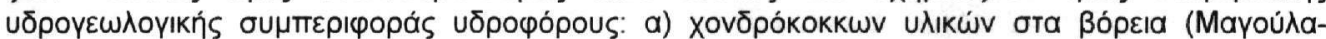

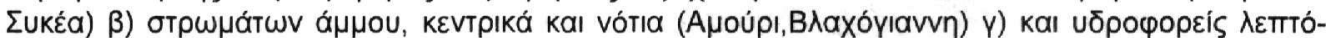

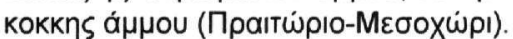

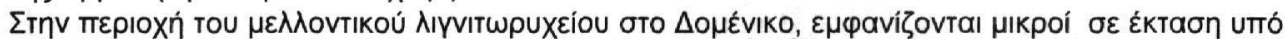

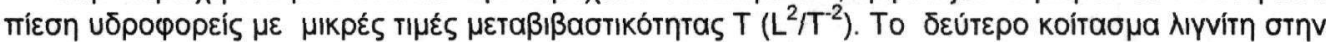

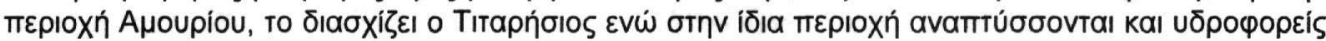

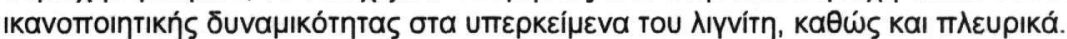

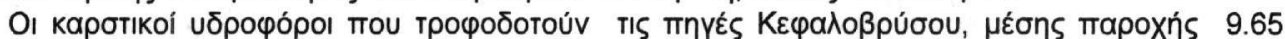

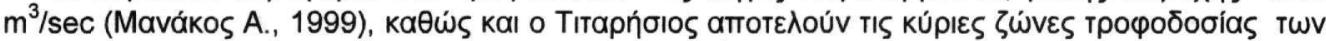

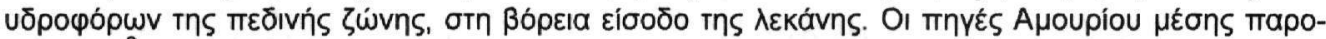

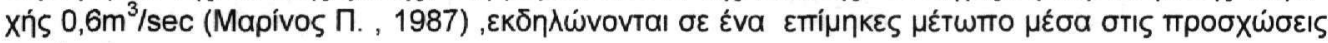

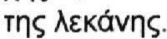

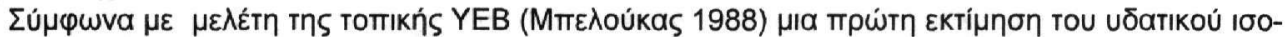

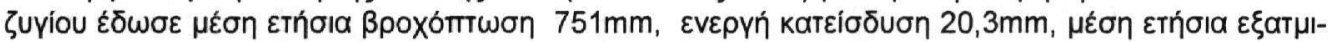

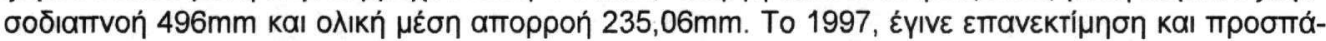

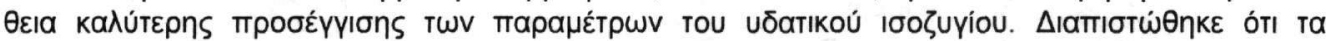

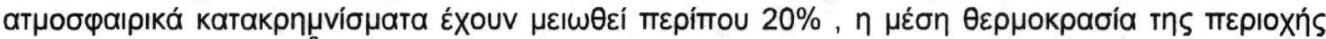

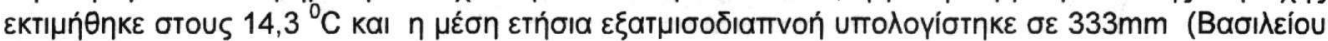
1997)

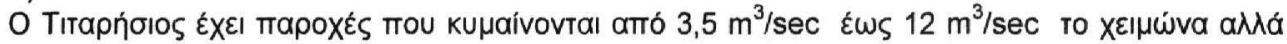

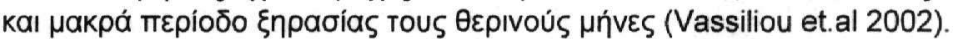

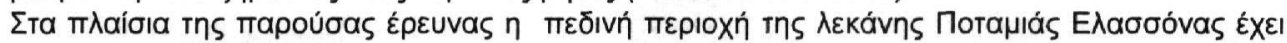

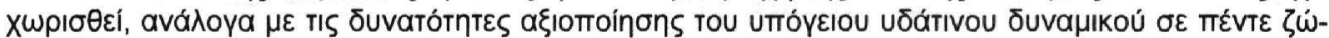

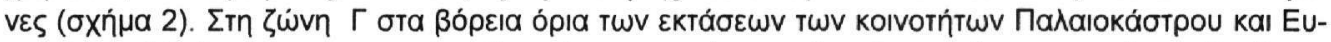

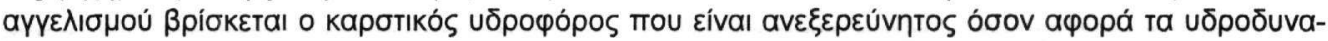

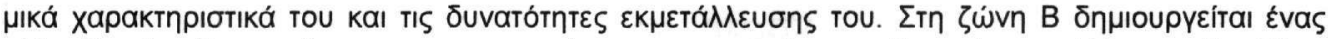

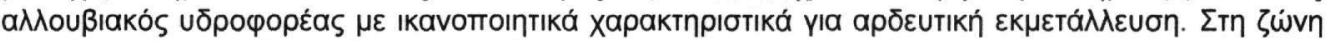

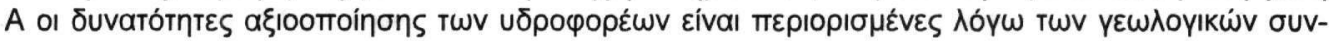

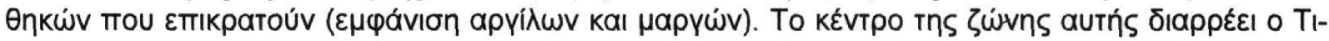

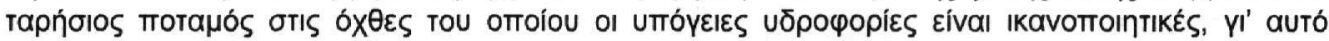

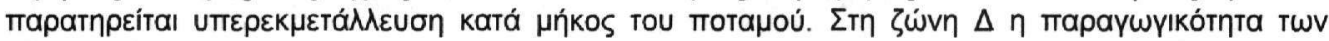

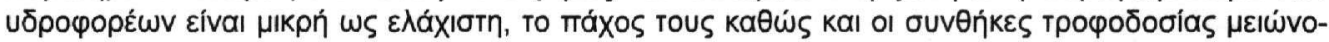

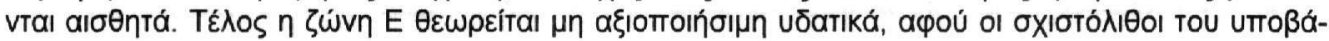

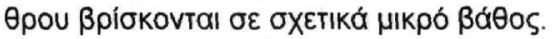

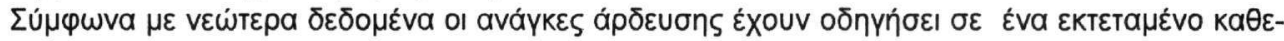

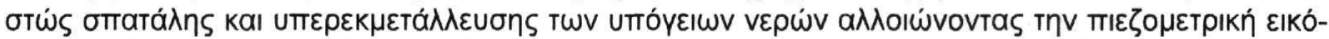

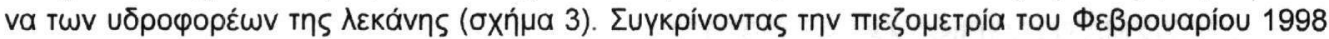

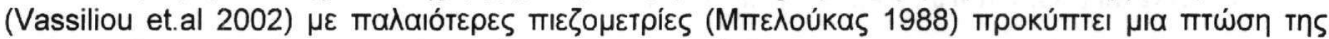

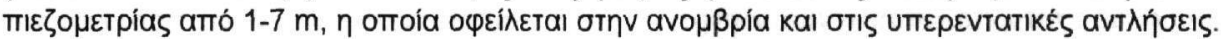

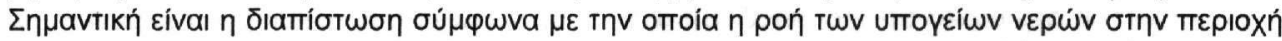

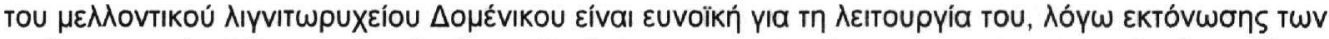

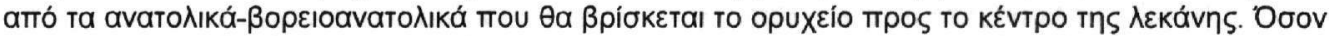

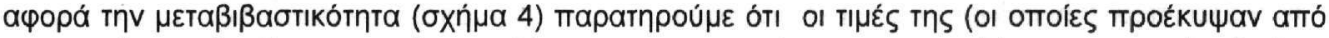

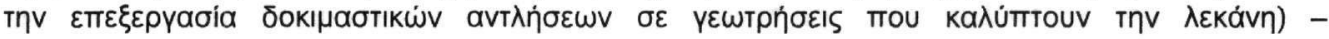

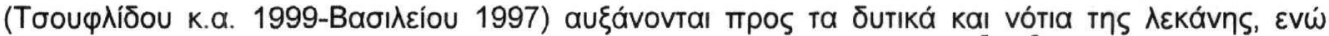

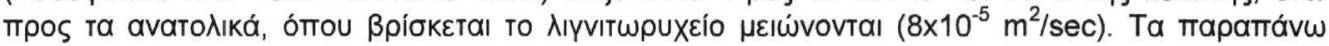




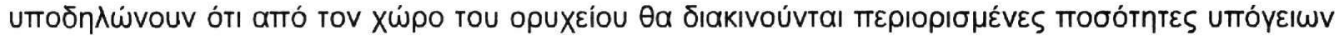

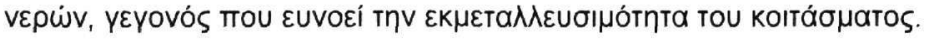

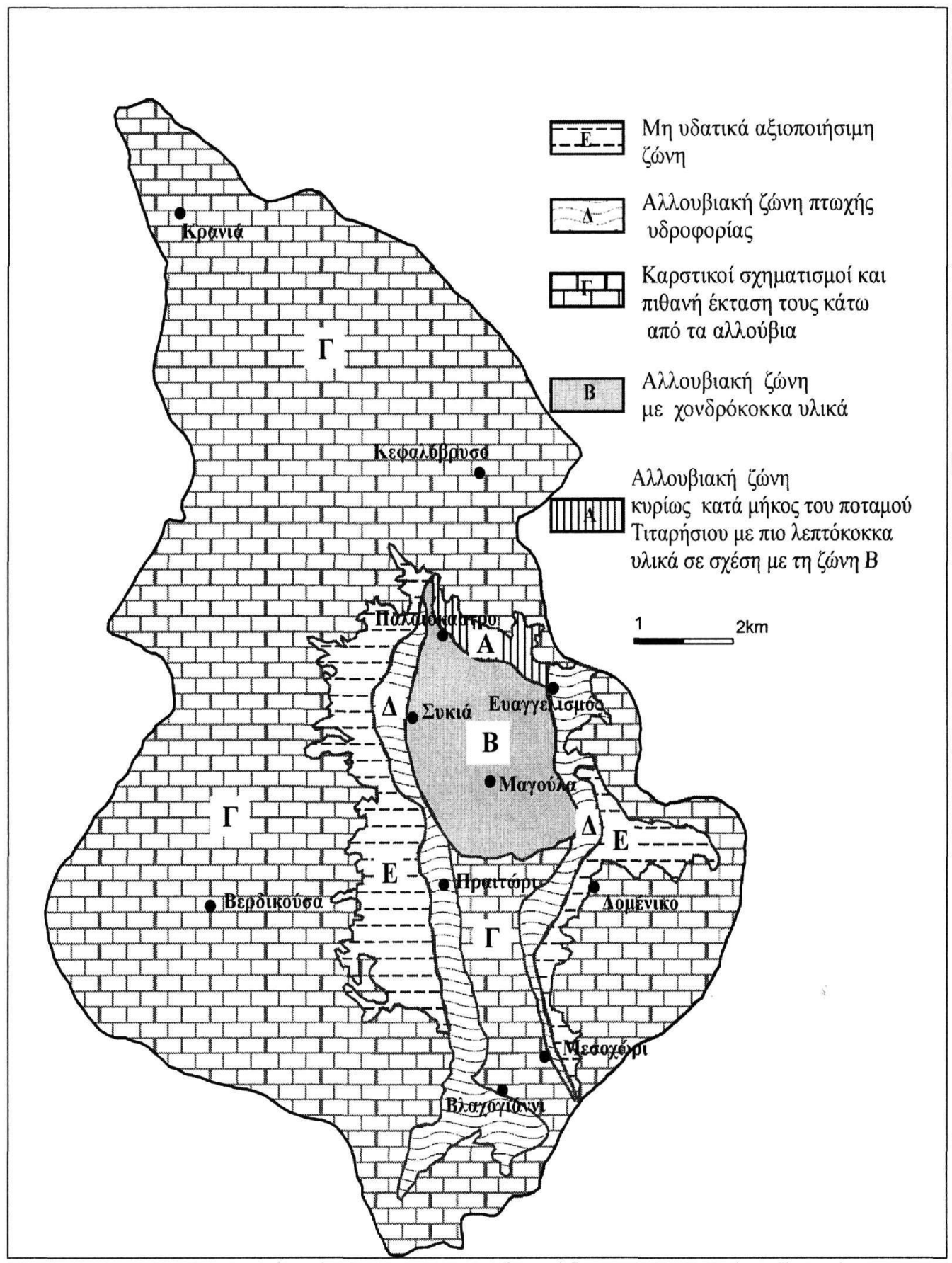

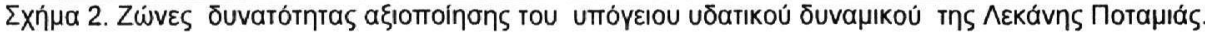




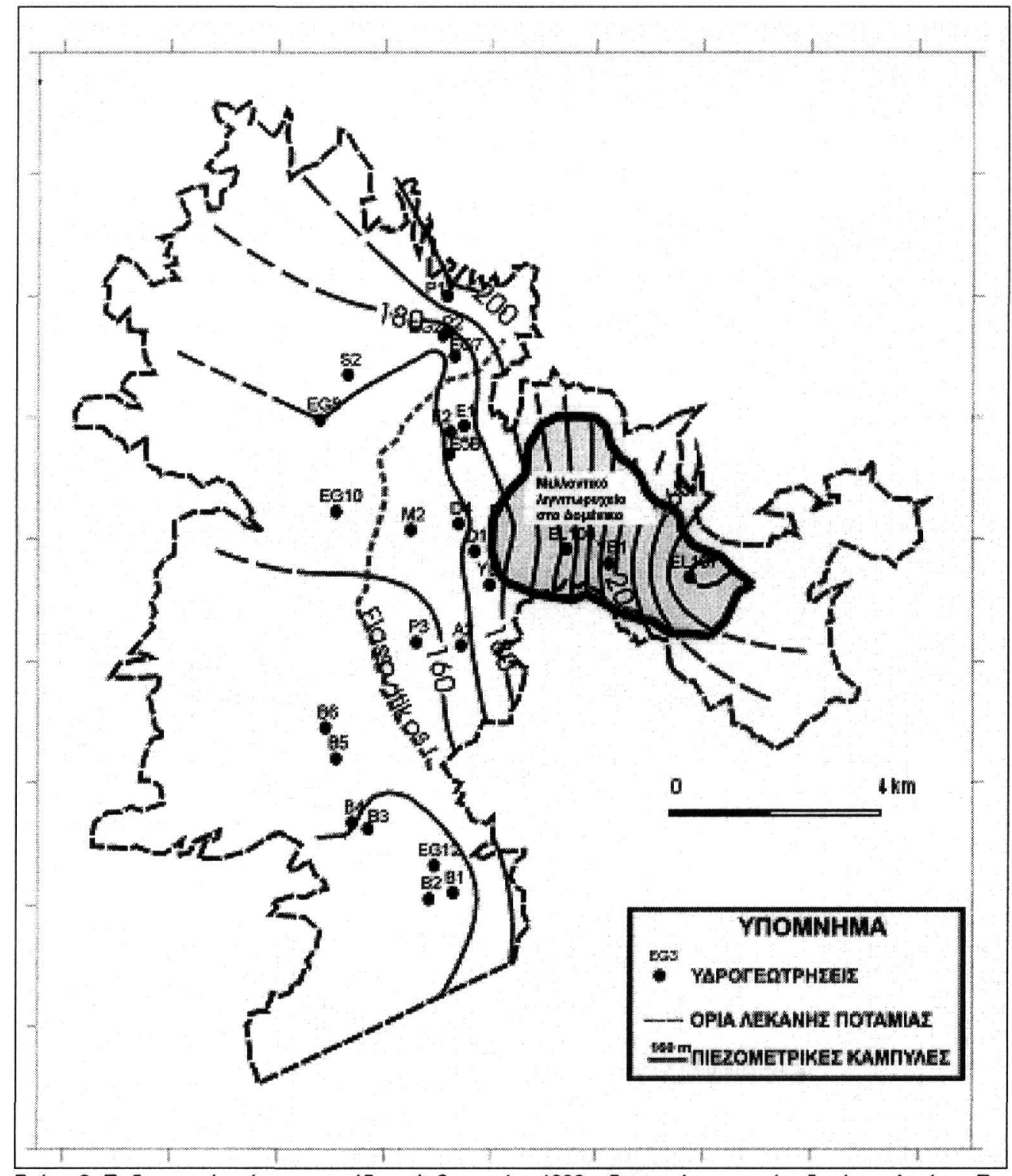

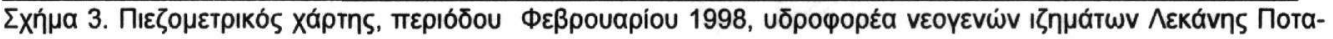
ulá́s. 


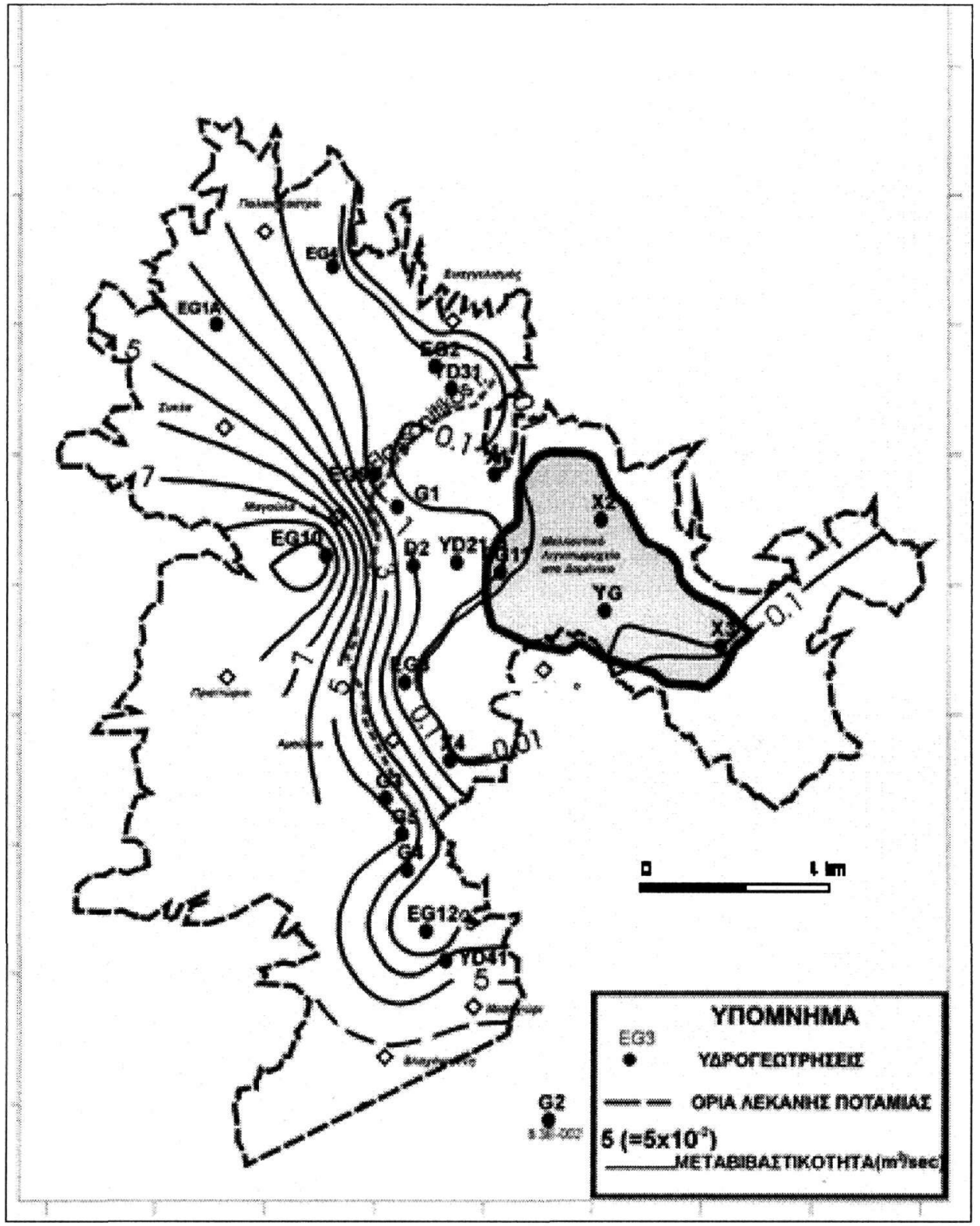

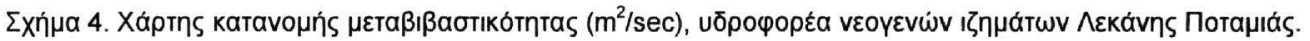

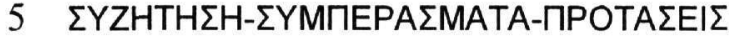

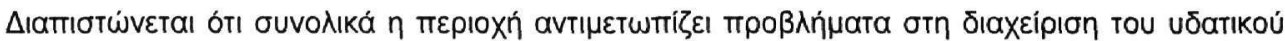

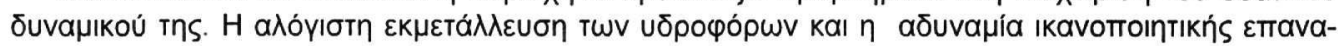

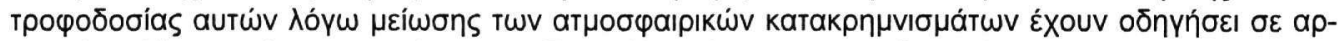

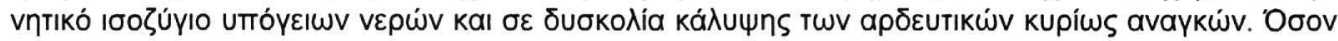

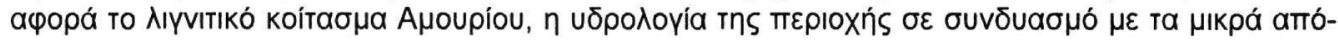




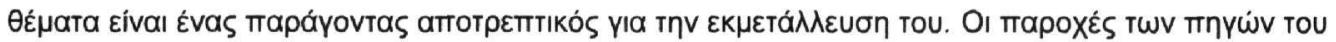

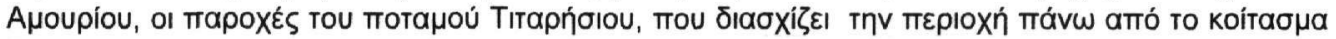

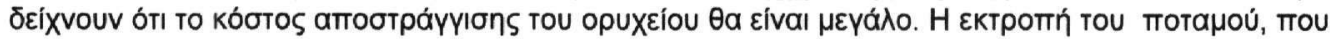

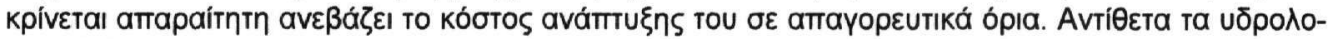

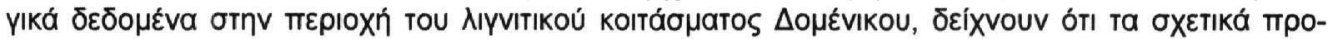

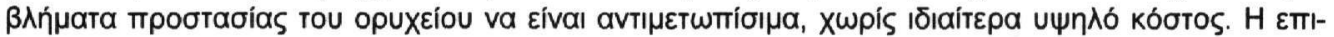

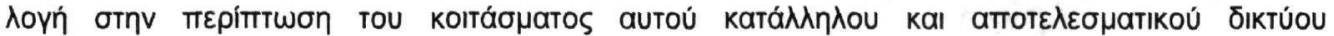

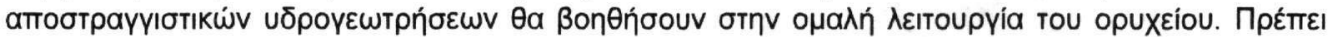

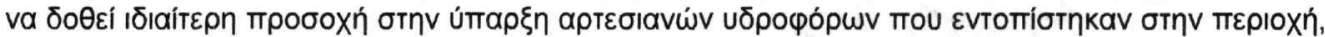

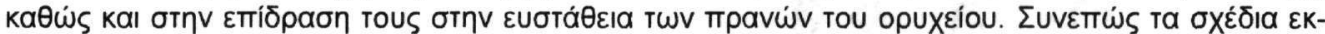

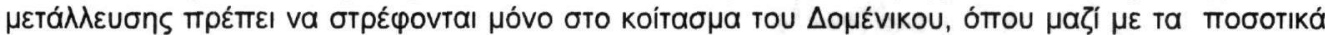

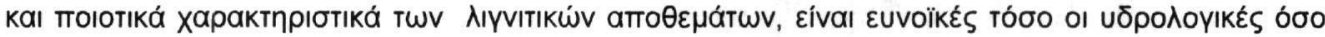

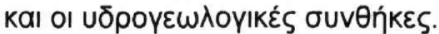

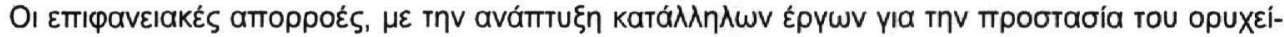

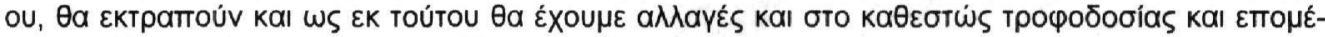

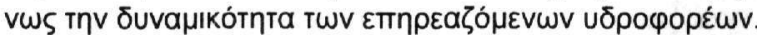

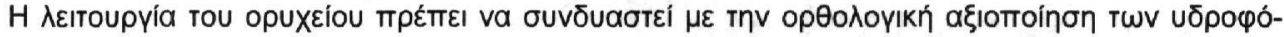

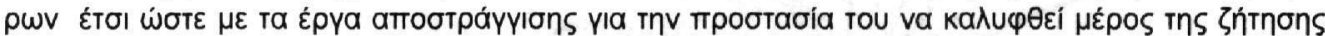

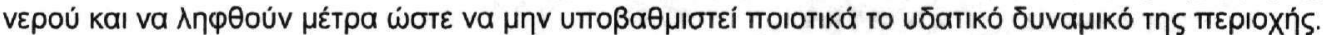

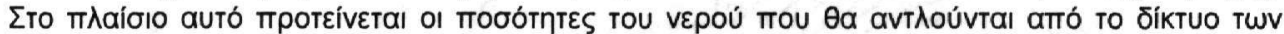

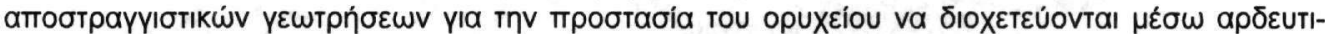

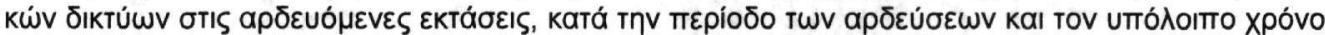

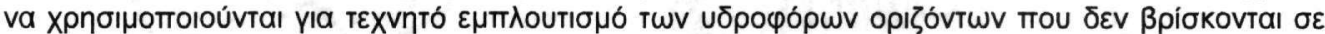

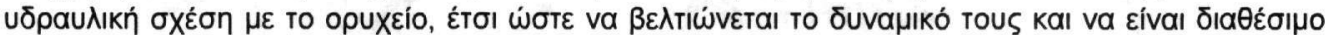

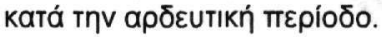

\section{ANAФOPE $\Sigma$}

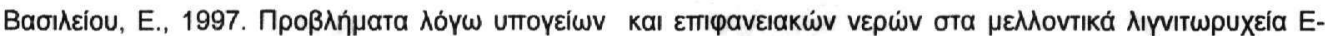

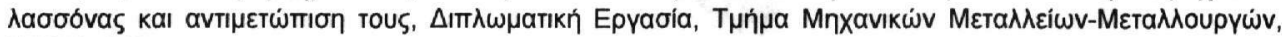
E.M.П., Aөńva.

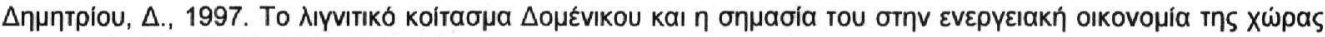

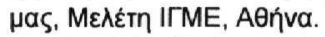

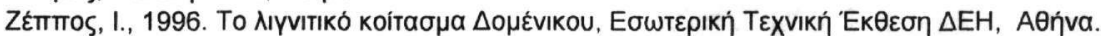

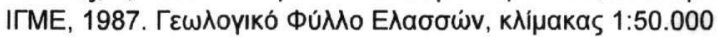

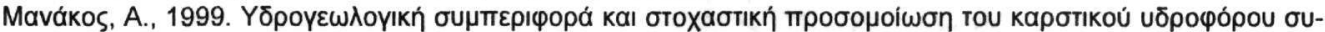

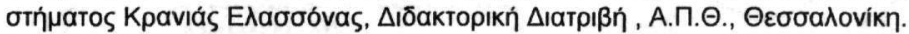

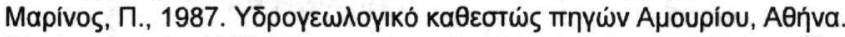

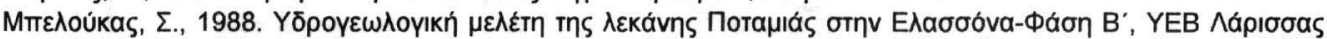
lavouápıos 1988, ^ápıбa.

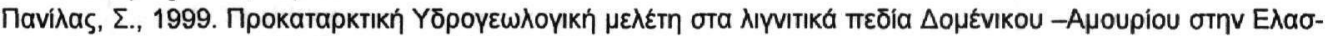

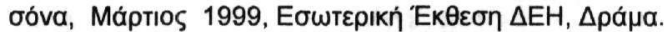

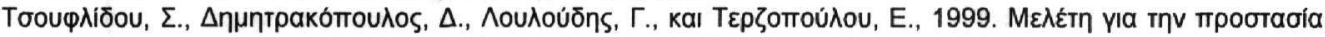

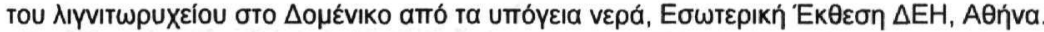

Vassiliou, E., Koumantakis, I., and Dimitrakopoulos, D., 2002. Hydrogeological conditions associated with the future exploitation of lignite mine in Potamia basin. Thessaly, Central Greece, Proceedings of the 17th Congress of the Carpathian-Balkan Geological Association, Bratislava, Slovakia. 


\title{
Hydrogeological conditions of Potamia Basin, Central GREECE, ASSOCIATED WITH THE PROSPECTIVE LIGNITE EXPLOITATION OF THE AREA
}

\author{
Vassiliou E. ${ }^{1}$, Koumantakis I. ${ }^{1}$, Dimitrakopoulos D ${ }^{2}$, and Grigorakou E. ${ }^{1}$ \\ 1 Department of Geological Science, School of Mining Engineer-Metallurgy, National Technical \\ University of Athens, Iroon Polytexneiou 9, GR 15780 Zografou, Athens, mmgpev@central.ntua \\ 2 Public Power Corporation of Greece, Kifisou \& Dirahiou 89, GR 10443 Athens, dei- \\ teym@otenet.gr
}

In Elassona Hydrological Basin, an area of $85 \mathrm{Km}^{2}$ in Central Greece, two lignite deposits, Domeniko and Amourio, of $160 \times 10^{6}$ th of lignite have been found. The exploitation process of the future open pit lignite mines is highly connected with the existence of surface and ground water in the area. The exploitation of these two lignite deposits will cause changes of the natural and human environment of the area.

In this paper the hydrogeological conditions and the hydrodynamic status of surface and ground water of the basin are described. A water management system of the water coming from dewatering process is suggested. 